\title{
Impaired Peripheral Nerve Regeneration in a Mutant Strain of Mice (Enr) with a Schwann Cell Defect
}

\author{
Erick M. Rath, ${ }^{1,2,3}$ Donna Kelly, ${ }^{1}$ Thomas W. Bouldin, ${ }^{1,2,4}$ and Brian Popko ${ }^{1,2,5,6}$ \\ ${ }^{1}$ Brain and Development Research Center, ${ }^{2}$ Curriculum in Neurobiology, Departments of ${ }^{3}$ Oral and Maxillofacial \\ Surgery, ${ }^{4}$ Pathology, and ${ }^{5}$ Biochemistry and Biophysics, and ${ }^{6}$ Program in Molecular Biology and Biotechnology, \\ University of North Carolina, Chapel Hill, North Carolina 27599-7250
}

Schwann cell-axon interactions in the development, maintenance, and regeneration of the normal peripheral nervous system are complex. A previously described transgene-induced insertional mutation (BPFD\#36), now referred to as Enervated (Enr), results in disrupted Schwann cellaxon interactions. In this report, after a crush or transection injury to Enr peripheral nerves, we demonstrate impaired nerve regeneration. There are fewer myelinated fibers per $\mathrm{mm}^{2}$ and thinner myelin sheaths surrounding regenerating axons in the nerves of homozygous mutant mice compared to wild type mice at $28 \mathrm{~d}$ after crush injury to the sciatic nerve. Abnormal Schwann cell-axon interactions remain in Enr/Enr animals as evidenced by the relatively frequent ultrastructural finding of unmyelinated large diameter axons in the regenerating nerves. Additionally, nerve graft experiments indicate that the impairment in regeneration is due to a Schwann cell defect. Morphologic and morphometric findings in conjunction with molecular analysis of regenerating nerves suggest that the Enr defect causes a disruption in the ability of "early" Schwann cells to differentiate to a more mature phenotype. In mutant homozygous and wild type nerves at $7 \mathrm{~d}$ after crush injury there are similar levels of mRNA for the lowaffinity nerve growth factor receptor, but in the mutant homozygous regenerating nerves there is 11-fold less mRNA for glial fibrillary acidic protein, a more mature phenotypic marker of Schwann cells. This Schwann cell differentiation defect likely accounts for both the peripheral neuropathy and impaired nerve regeneration observed in Enr mice.

[Key words: Schwann cell, impaired nerve regeneration, transgenic, mouse mutant, peripheral neuropathy, nerve graft]

Schwann cells (SCs) and axons in the peripheral nervous system (PNS) exhibit an intimate, conjoining relationship. Reciprocal signaling and modulation of gene expression by interacting ax-

\footnotetext{
Received Apr. 7, 1995; revised June 20, 1995; accepted June 28, 1995.

We are grateful to Nelson Goines and Janice Weaver for technical support, to Dr. John Zuniga for surgical assistance, and to Dr. C. Robert Bagnell and the UNC Department of Pathology for microscopic and morphometric assistance. We also thank Drs. Ken McCarthy and George DeVries for the critical review of the manuscript. This work was supported by NIH Grants ESO1104 (B.P. and T.W.B.), DE07509 (E.M.R.), and the 1994/95 Oral and Maxillofacial Surgery Foundation Research Fellowship (E.M.R.). B.P. is a recipient of a NIH Research Career Development Award NS 016.37 from NINDS.

Correspondence should be addressed to Dr. Brian Popko, Brain and Development Research Center, CB\# 7250, University of North Carolina at Chapel Hill, Chapel Hill, NC 27599-7250.

Copyright (C) 1995 Society for Neuroscience $0270-6474 / 95 / 157226-12 \$ 05.00 / 0$
}

ons and SCs occurs throughout development and maintenance of the PNS (Bray et al., 1981; Bunge, 1993; Griffin el al., 1993; Mezei, 1993; Reynolds and Woolf, 1993; Martini, 1994). As reviewed in Jessen and Mirsky (1991), at embryonic day 14-15 (E14-15), proliferating SC "precursors" express several antigenic markers, such as the low-affinity NGF receptor (NGFr), the expression of which appears to be axonally controlled. At embryonic day 16 the majority of SC "precursors" continue to express NGFr, but now also become S100 positive "early" SCs. Around embryonic day 18 these "early" SCs begin to express the antigenic differentiation marker, O4 (sulfatide), and glial fibrillary acidic protein (GFAP) and are classified as "bipotential" SCs. In contrast to NGFr, expression of GFAP appears to be intrinsically regulated, such that axonal contact is not required for its appearance (Jessen et al., 1990). Mature nonmyelinating or myelinating SCs are derived from these "bipotential" SCs. There is a clear phenotypic distinction between "early" SCs which express NGFr predominantly near E16, and the "bipotential" SCs that express NGFr, O4, and GFAP beginning at about E18 (Jessen and Mirsky, 1991).

The temporal pattern of SC differentiation is important in peripheral nerve development (Stewart et al., 1993). During PNS development, axon outgrowth is quickly followed by precursor $\mathrm{SC}$ proliferation and migration. As differentiation progresses, bipotential SCs are signaled by axons either to cease proliferation and establish a 1:1 myelinating relationship with a larger diameter axon, or to ensheath a number of small diameter axons (Sanes, 1989; Jessen and Mirsky, 1991; Gould et al., 1992; Mezei, 1993; Webster, 1993). Extracellular matrix and basal lamina components are critical for proper SC differentiation and mature function (Bunge, 1993). Nonmyelinating SCs maintain an embryonic pattern of NGFr expression throughout development and into adulthood, while myelinating cells are characterized by down regulation of NGFr and GFAP, and up regulation of myelin proteins.

When peripheral nerves are subjected to a severe injury such as crush or transection that results in disconnection of axons from their cell body, the axons degenerate distal to the site of injury (Wallerian degeneration) (Griffin and Hoffman, 1993). Molecular and cellular events that occur during normal peripheral nerve development are thought to reoccur during the subsequent regeneration of the peripheral nerve following injury (Griffin and Hoffman, 1993). During Wallerian degeneration, SCs revert morphologically and molecularly to an undifferentiated early state and again proliferate. As in embryonic development these SCs express NGFr, but also remain S100 positive 
(Jessen and Mirsky, 1991). Myelinating and nonmyelinating SCs deprived of axonal contact by Wallerian degeneration lose surface expression of the 04 antigen.

Loss of axonal contact also results in increased expression of trophic factors and their receptors, cell adhesion molecules, and extracellular matrix constituents by resident, dedifferentiated, proliferating SCs within the bands of Bünger in the distal stump (Johnson et al., 1988; Fawcett and Keynes, 1990). This is believed to provide an environment supportive of axonal regeneration (Taniuchi et al., 1986; Johnson et al., 1988; Bunge, 1993; Griffin and Hoffman, 1993). In a regenerating peripheral nerve, SC processes provide guidance to sprouting axons as they grow and extend toward target tissue (Son and Thompson, 1995). Moreover, the absence of SCs distal to an injury site results in less neurite outgrowth (Hall, 1986). Zhao and Kerns (1994) have shown that early activation of SCs contributes to enhanced regeneration and maturation of the PNS. As regeneration successfully proceeds, SCs again differentiate and display the more mature phenotype of nonmyelinating and myelinating cells (Bray et al., 1981).

A transgenic mouse line (BPFD\#36) with an autosomal recessive, adult-onset neuromyopathy that is likely due to the insertional disruption of an endogenous gene by the transgene integration event has been generated in our laboratory (Kelly et al., 1994). We now refer to this line of mice as "Enervated" (Enr), which means impaired, or lacking strength or vitality. Mice homozygous for the Enr mutation display peripheral neuropathy and muscle degeneration (Kelly et al., 1994). The phenotype of these mice becomes apparent at about six weeks of age when homozygous (Enr/Enr) mice demonstrate dragging or splaying of their hind limbs. Morphologically, nerves and nerve roots in the homozygous mice show abnormal Schwann cellaxon interactions, as evidenced by large bundles of bare, juxtaposed unmyelinated axons among the myelinated fibers. Within these groups of bare axons there are occasional axons large enough to be myelinated. In this report, we demonstrate that in addition to the peripheral neuropathy, Enr/Enr mice show impaired peripheral nerve regeneration after a crush injury, and that abnormal SC-axon interactions remain following the regenerative efforts. Furthermore, grafting of wild type nerves into Enr/Enr mice corrected the defect in nerve regeneration within the graft, and in combination with molecular studies, indicates a primary $\mathrm{SC}$ defect. These studies also suggest that the Enr mutation disrupts the ability of SCs to differentiate from the "early" SC stage to the "bipotential" SC stage.

\section{Materials and Methods}

Animals, anesthesia, and surgery. The mice described here have been previously reported as the BPFD\#36 line of transgenic mice (Kelly et al., 1994). We have adopted a new, more descriptive, terminology for these mice where enervated $(E n r)$ indicates the mutated allele that is associated with muscle degeneration and peripheral nerve pathology. Enervated is derived from Latin "nervare" (of nervus sinew) and is defined as impaired, or lacking strength or vitality, or to deprive of force. Thus, enervated describes the phenotype of mice homozygous for the transgene array as related to their previously reported neuromuscular disorder, and also summarizes the ability of the peripheral nerves in these mice to regenerate. Two variations of these mice are maintained: (1) a strain in which we have crossed the mutation back to the C57BL/6J background twice, each time followed by sibling matings, and (2) a C57BL-6J/SJL strain in which the strain described above was crossed once to SJL mice followed by sibling matings. These crosses were carried out in an attempt to increase the number of homozygous mice born from heterozygous crosses which has been consistently less than $10 \%$ in both inbred and outbred strains (homozygotes do not breed), indicating either embryonic or early neonatal lethality in a proportion of the conceived mice homozygous for the Enr mutation. The neuromuscular phenotype is identical in both strains.

Prior to surgical intervention, mice were anesthetized with intraperitoneal Avertin ( $0.4 \mathrm{gm}$ tribromoethanol $/ \mathrm{kg}$ body weight). All surgical manipulations were performed under sterile conditions on 10-14 week old $E n r / E n r,+/ E n r$ and $+/+$ littermates or progeny of littermates. For sciatic nerve crushes, the left sciatic nerve was surgically exposed at its exit from the vertebral canal; \#55 jeweler's forceps were dipped in India ink and the sciatic nerve crushed as it coursed the foramen. The crush was maintained for $15 \mathrm{sec}$ and a type 2 to type 3 nerve injury (Sunderland, 1990) administered such that the epineurium remained intact. The mandibular branch of the facial nerve and the sural branch of the sciatic nerve were similarly crushed in different animals.

Mice were allowed to survive for 1, 4 , or 8 weeks depending on the experimental paradigm. One mouse each from the $E n r / E n r,+/ E n r$, and $+1+$ groups were sacrificed at 1 week postcrush for sciatic nerve morphology. Three $E n r / E n r$, four $/ / E n r$, and three $1 / 1$ mice were sacrificed at 4 weeks postinjury for sciatic nerve morphology and morphometry. One mouse from each of the three groups was sacrificed at 8 weeks for sciatic nerve morphology. Two Enr/Enr and two $+/+$ mice received both facial and sural nerve crushes for morphological examination at 4 weeks postoperatively. Five $+/+$ and five Enr/Enr sciatic nerves were crushed and removed $7 \mathrm{~d}$ postoperatively for total RNA isolation. Likewise, five $+1+$ and five Enr/Enr sciatic nerves were crushed and removed 28 d postoperatively for total RNA isolation. Uninjured contralateral nerves were also isolated and used as controls.

Nerve graft experiments were performed on the inbred mice with graft harvests and transplants occurring between siblings. The left sciatic nerve was surgically exposed from the sciatic notch distally. The nerve was dissected free from surrounding mesoneurium from the sciatic notch extending distally for approximately $1 \mathrm{~cm}$. Surrounding muscles were retracted and the nerve placed on a thin latex platform for adequate exposure. Nerves from animals to receive the sciatic nerve grafts (recipients) were not further manipulated until just prior to transplantation. The exposed nerves were continuously bathed in sterile $0.9 \%$ normal saline during harvesting and subsequent transplantation. An approximately $7 \mathrm{~mm}$ segment of sciatic nerve was treated as described above and harvested immediately from the donor and placed in cool sterile $0.9 \%$ normal saline. A $7 \mathrm{~mm}$ segment of the sciatic nerve was then immediately removed from the recipient animal and the donor nerve placed into the recipient animal and nerve ends approximated and sutured into place with two 10-0 nylon black filament sutures on an AU-8 bi curve cutting needle (Alcon) at each anastomosis site. All surgical procedures were performed with microscopic visualization. All mice receiving allografts were immunosuppressed with cyclosporin A (Sandimmune, Sandoz, East Hanover, NJ) dissolved in $99 \%$ cremaphor EL (Sigma)/1\% ETOH, $5 \mathrm{ng} / \mathrm{hr}$ delivered by subcutaneous microosmotic pump (Alzet pump model 2002, Alza, Palo Alta. CA) to minimize any possible host versus graft response in the noncongenic siblings. Mice were anesthetized, and pumps and pharmacologic agent were removed at 2 weeks and replaced for the remaining 2 weeks prior to sacrifice. Two $+/+$ sciatic nerve segments were removed and autografted. Additionally, two $+/ /$ mice received $+/+$ allografts. Two $+/$ + mice received $+/ E n r$ allografts, and two $+1+$ mice received $E n r / E n r$ sciatic nerve allografts. Two $+/ E n r$ and two Enr/Enr mice received +1 + allografts. All mice were sacrificed 4 weeks posttransplantation.

Light/electron microscopy. Sciatic, facial, and sural nerves to be examined morphologically and/or morphometrically were removed from mice perfused through the left cardiac ventricle with an ice-cold solution of $4 \%$ paraformaldehyde and $2.5 \%$ glutaraldehyde in $0.1 \mathrm{~m}$ sodium phosphate buffer, $\mathrm{pH} 7.4$. Nerves were removed and orientation maintained and immersion fixed overnight at $4^{\circ} \mathrm{C}$ in the same fixative solution. Tissues were rinsed $3 \times$ in $0.05 \mathrm{M}$ sodium phosphate buffer, $\mathrm{pH}$ 7.4. Tissues were then postfixed in Dalton's Osmium Solution (4\% $\mathrm{K} 2 \mathrm{Cr} 2 \mathrm{O} 7 \mathrm{pH} 7.35,3.4 \% \mathrm{NaCl}, 4 \% \mathrm{OsO} 4$ in a $1: 1: 2$ ratio) for $2 \mathrm{hr}$. Tissues were then alcohol dehydrated, propylene oxide treated, and infiltrated and subsequently embedded in Spurr`s resin (Polyscience). One micrometer thick cross-sections were cut and stained with para-phenylene diamine for light microscopic use (photomicrographs, and morphometry). The sciatic nerves from the 4 week postcrush groups were examined morphologically and morphometrically. All other nerves were examined morphologically. Thin cross sections from the 4 week crushed sciatic nerves were cut and uranyl acetate and lead citrate stained for electron microscopy with a Zeiss $10 \mathrm{~A}$ electron microscope. 
Morphometry. A semiautomated method for quantification of myelinated nerve fiber data was used similar to that described by Auer (1994). Sequential images of light microscopic sections $3 \mathrm{~mm}$ distal to the crushed site of the sciatic nerve from Enr/Enr, $+/ E n r$, and $+1+$ mice, and corresponding sections from contralateral uncrushed sciatic nerves were captured from a Nikon Microphot-FXA microscope at $125 \times$ magnification on a personal computer with the IMAGE-PRO II version 2.2 software program (Media Cybernetics). Images were transferred to a MacIntosh Quadra 840AV computer for morphometric analysis using the NIH IMAGE v. 1.54 software program (National Institutes of Health public domain). Myelin was highlighted and axon perimeter and area calculated and outer fiber perimeter and total fiber area calculated. These four measurements were obtained for every myelinated axon within the processed image. Myelin area, fiber diameter, axon diameter, myclin thickness, and axon area measurements for each nerve fiber were mathematically derived from the original four measurements/axon. In addition, the total number of myelinated axons $/ \mathrm{mm}^{2}$ and the mean percentage of the image area occupied by axon and the mean percentage of the image area occupied by myelin associated with axons within each $2.1 \mathrm{~mm}^{2}$ processed image were determined.

Statistics. Statistical analysis on morphometric data from crushed sciatic nerves 4 weeks postoperatively was calculated for $n=3,4,3$, for $E n r / E n r,+/ E n r$, and $+/+$ nerves, respectively. Corresponding contralateral control nerve morphometric data was calculated based on $n=$ $3,3,3$, for the three groups. Mean values for each measured parameter for each animal were determined and placed in their appropriate group where single factor ANOVA was performed on Windows MICROSOFT EXCEL software.

Northern analysis. RNA was prepared using the guanidium thiocyanate method of Chirgwin et al. (1979). Northern blots were prepared as described by Popko et al. (1987). Crushed or uninjured sciatic nerves of wild type or homozygous mutant mice were isolated either $7 \mathrm{~d}$ or $28 \mathrm{~d}$ after injury. Probes for hybridization were ${ }^{32} \mathrm{P}$ labeled by either the random priming method of Feinberg and Vogelstein (1983), or by the thermal cycling method of Jansen and Ledley (1989). Hybridizations and washes were performed as previously described (You et al., 1991). cDNAs for GFAP (Lewis et al., 1984), NGFr (Radeke et al., 1987), SCIP (Monuki et al., 1989), lysozyme (Cross et al., 1988; Venezie et al., 1995), and ApoE (McLean et al., 1983) were used as probes. A pair of oligonucleotides specific for $18 \mathrm{~S}$ ribosomal RNA (rRNA) were ${ }^{32} \mathrm{P}$ end labeled to evaluate relative levels of total RNA present within each lane.

\section{Results}

\section{Peripheral neuropathy in mice homozygous for the Enr mutation}

Kelly et al. (1994) described in the sciatic nerve and spinal roots of homozygous mutant mice, large bundles of bare, juxtaposed, small diameter unmyelinated axons, which had no intervening SC cytoplasm. In the present study of 10-14 week old Enr/Enr mice, further examination of the sciatic nerve just distal to its exit from the vertebral column reveals additional ultrastructural findings. Not only are there bundles of small axons without intervening SC cytoplasm, but as shown in Figure $1 A$, there are also bundles of larger diameter unmyelinated axons, and isolated SC-ensheathed large unmyelinated axons (Fig. $1 B$ ). Also present are axons with redundant myelin sheaths and dystrophic axons (Fig. $1 C$ ). Early evidence of enlarged SC-axon networks, which are often observed in situations in which there is early axonal disease (Spencer and Thomas, 1974) (Fig. IA), are present within a small number of myelinated axons within the peripheral nerves of homozygous and heterozygous $(+/ E n r)$ mice. Bundles of small diameter axons enclosed within a single myelin sheath (Fig. $1 D-F$ ), similar to those previously described as rarely occurring in normal and certain strains of mutant mice (Waxman, 1968; Okada et al., 1977; Shetty and Antia, 1980; Beuche and Friede, 1984) are also frequently present. No myelinated bundles were observed in control wild type $(+/+)$ sciatic nerves. The ultrastructural abnormalities are also observed in $+/ E n r$ mice (data not shown), although much less frequent than in Enr/Enr mice, and are not observed in $+/+$ littermate controls.

\section{Impaired regeneration following nerve crush}

To examine the effect of abnormal SC-axon interactions in Enr mice on nerve regeneration, the left sciatic nerves of $10-14$ week old $+/+,+/ E n r$, and Enr/Enr mice were crushed and studied morphologically 1, 4, or 8 weeks later. Light microscopic evaluation of the crushed nerves from $+1+$ and Enr/Enr mice at 1 week after injury shows a similar progression of Wallerian degeneration (data not shown). Four weeks after crush, nerve regeneration is most advanced in $+/+$, less advanced in $+/ E n r$, and least advanced in Enr/Enr mice (Figs. 2A-D). The Enr/Enr nerves (Fig. 2D) have fewer and smaller myelinated nerve fibers. Additionally, there are more myelin ovoids and lipid droplets in cells in the Enr/Enr nerves compared to the $+/+$ nerves (Fig. 2B). Ultrastructurally, the Enr/Enr nerves contain large amounts of myelin debris and intracytoplasmic lipid droplets (Fig. 3C,D). Also notice the large unmyelinated axon in Figure $3 C$ (arrowhead), while nearby there are smaller diameter myelinated axons. Unmyelinated large diameter axons are noted relatively frequently within regenerating $E n r / E n r$ nerves.

To quantitate differences in nerve regeneration among the three genotypic mice, $+/+,+/ E n r$, and Enr/Enr sciatic nerves were studied morphometrically 1 month after crush. Table 1 lists the values obtained from nerves pooled from each genotypic mouse for the crushed nerves and the contralateral uninjured nerves. For uninjured nerves, the percentage of nerve area occupied by axon-associated myelin (i.e., \% myelin), which is related to the number of myelinated axons per $\mathrm{mm}^{2}$ and the thickness of the myelin around these axons, is significantly different among the three groups, with the smallest percentage of myelin in Enr/Enr uninjured nerves. There is a slight trend toward the Enr/Enr nerves having fewer myelinated axons per $\mathrm{mm}^{2}$ and a smaller myelin-sheath thickness, but these differences do not reach significance.

Six of the parameters evaluated from crushed nerves show significant differences (see Table 1: crush) among the three genotypes. There are fewer myelinated axons per $\mathrm{mm}^{2}$, smaller fiber diameter (axon diameter plus myelin), smaller myelin thickness, and smaller percentage myelin and smaller percentage axon in homozygous animals. The differences in mean axon diameter are not significant, but trend toward smaller values in Enr/Enr mice. There are no significant differences between $+/$ + and $+/ E n r$ nerves, although there is a trend toward fewer myelinated axons per $\mathrm{mm}^{2}$ and a corresponding smaller percentage myelin in $+/ E n r$ mice. The graphic analysis in Figure 4 represents the percentage of the total number of myelinated fibers counted in $1 / 1$ or Enr/Enr crushed sciatic nerves that fall within each bin extending from $0.5 \mu \mathrm{M}$ to $10 \mu \mathrm{M}$. There is a left shift (decrease) in the size of myelinated fibers for homozygous mice.

To evaluate if the impaired nerve regeneration in Enr/Enr mice is due to a delayed or slower regenerative response, injured left sciatic nerves from control and mutant mice were allowed to regenerate for 8 weeks after crush. The eight week time point was chosen because regeneration of normal mouse sciatic nerve is essentially complete at this time after injury (Tanaka et al., 1992). Eight weeks after nerve crush, the left hind limb of the Enr/Enr mouse was noticeably impaired compared to its contralateral hind limb. In contrast, the $+/+$ mouse had a normal gait and appearance, with no difference between right and left hind 

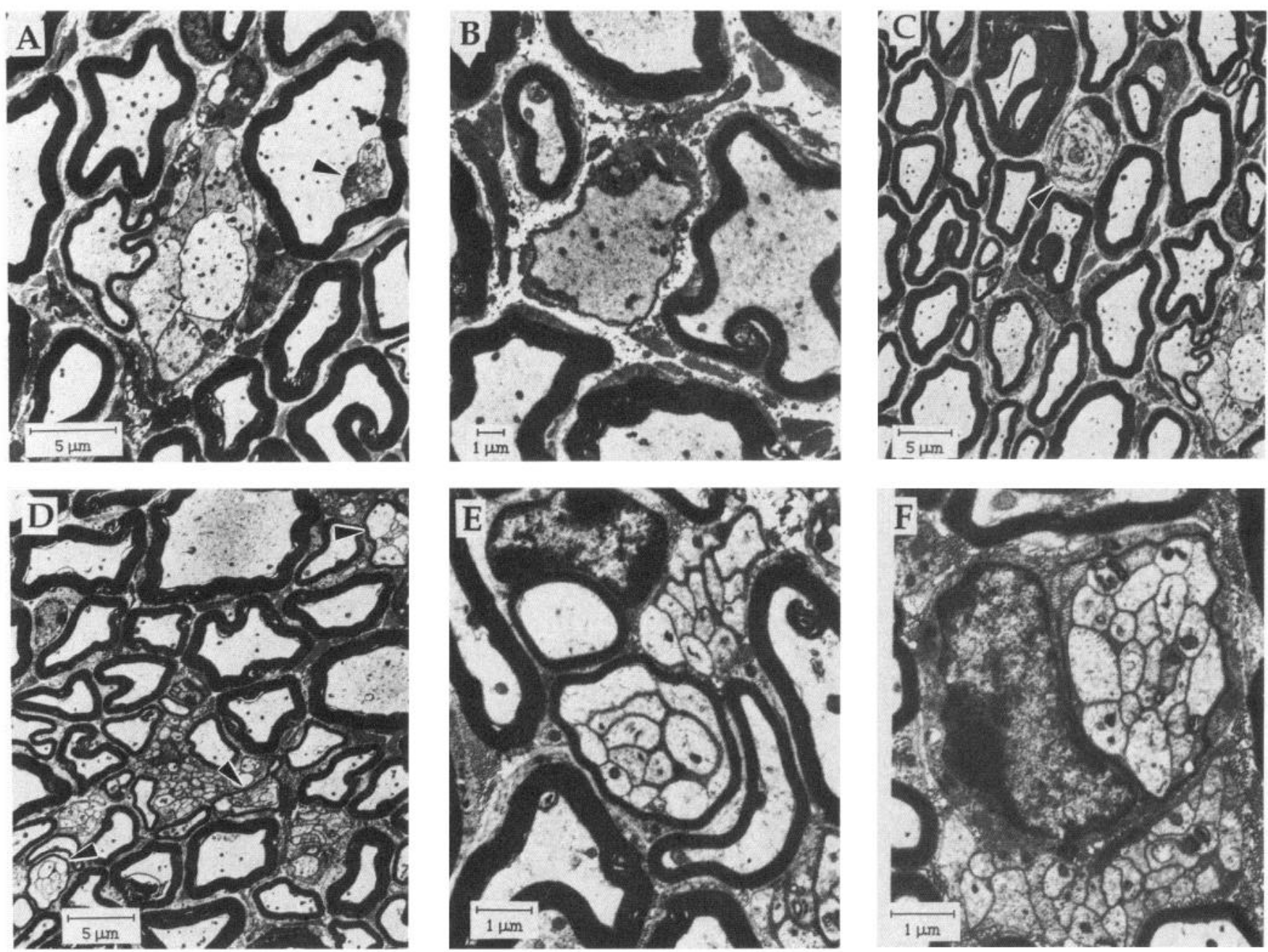

Figure 1. Peripheral neuropathy in Enr mice. Electron photomicrographs demonstrate disrupted 1:1 Schwann cell-axon relations in uninjured 1014 week old Enr/Enr sciatic nerves. Scale bars for each panel in lower left corner. A, Bundle of large, unmyelinated axons is shown centrally. Arrowhead shows an enlarged SC-axon network within a large myelinated axon. $B$, Single large diameter unmyelinated (or very thinly myelinated) axon. $C$, Multiple pathologic findings including the bundle of large diameter axons in A. Also notice the dystrophic axon indicated by the arrowhead, and the axon wrapped multiple times within a myelin sheath in the upper left. $D$, Within the $1100 \mu \mathrm{m}^{2}$ area shown here, there are three myelinated bundles of small diameter axons (arrowheads). E. Higher magnification view of a myelinated bundle of small diameter axons. $F$, A Schwann cell is associated with a bundle of small diameter axons. The bundle is partially surrounded by a thin myelin sheath. It is unknown if this represents a $\mathrm{SC}$ in the process of myelinating the bundle of axons, or a SC that has aborted its initial myelination efforts.

limbs. Light microscopy reveals lipid droplets in cells near the crush site in the $E n r / E n r$ nerve at 8 weeks after injury (Fig. 5B), although the number of cells and the amount of debris is less than that at 4 weeks postcrush (Fig. 2D). Lipid droplets in cells are not noted in the $+/+$ nerve 8 weeks after crush (Fig. $5 A$ ). In addition, it appears that the number and size of regenerating myelinated fibers at 8 weeks is less in the Enr/Enr mouse (Fig. $5 B$ ) than in the $+/+$ mouse (Fig. $5 A$ ). In summary, at 8 weeks after nerve injury, nerve regeneration in the Enr/Enr mouse does not equal the nerve regeneration in wild type nerves.

The sciatic nerve is a mixed nerve containing both sensory and motor fibers (Schmalbruch, 1986). To determine if the difference in sciatic nerve regeneration between Enr/Enr and $+/+$ mice demonstrated above might be attributed to a preferential inability of only one type of nerve fiber in Enr/Enr mice to regenerate, we crushed facial nerves which are predominantly motor (Shimozawa, 1975), or sural nerves which are predominantly sensory (Schmalbruch, 1986). Morphologically, both motor and sensory nerves in Enr/Enr mice display a similar degree of limited regeneration at 4 weeks postcrush compared to $+/+$ mice (data not shown).

\section{Nerve grafts results}

Nerve graft experiments have previously been used to distinguish between SC or axon defects in peripheral neuropathies (Aguayo et al., 1979; Perkins et al., 1981; de Waegh et al., 1992). We used this approach to further characterize the impaired regenerative capability of Enr peripheral nerves. We transplanted wild type SCs within a wild type donor sciatic nerve into wild type, $+/ E n r$, and $E n r / E n r$ recipient mice. We also transplanted $+/ E n r$ and $E n r / E n r$ nerves into $+/+$ recipients. When regenerating $+/+$ axons encounter a $+/+$ graft environment, regeneration proceeds well, both within the grafted segment (Fig. 6A) and within the endogenous nerve distal to the second anastomosis site (Fig. $6 F$ ). Regeneration also progresses well when Enr/Enr axons encounter $+/+$ SCs within $+/+$ grafts (Fig. $6 C$ ), but progresses very poorly within the distal endogenous $E n r / E n r$ nerves (Fig. $6 H$ ). When $+/+$ axons encounter an 

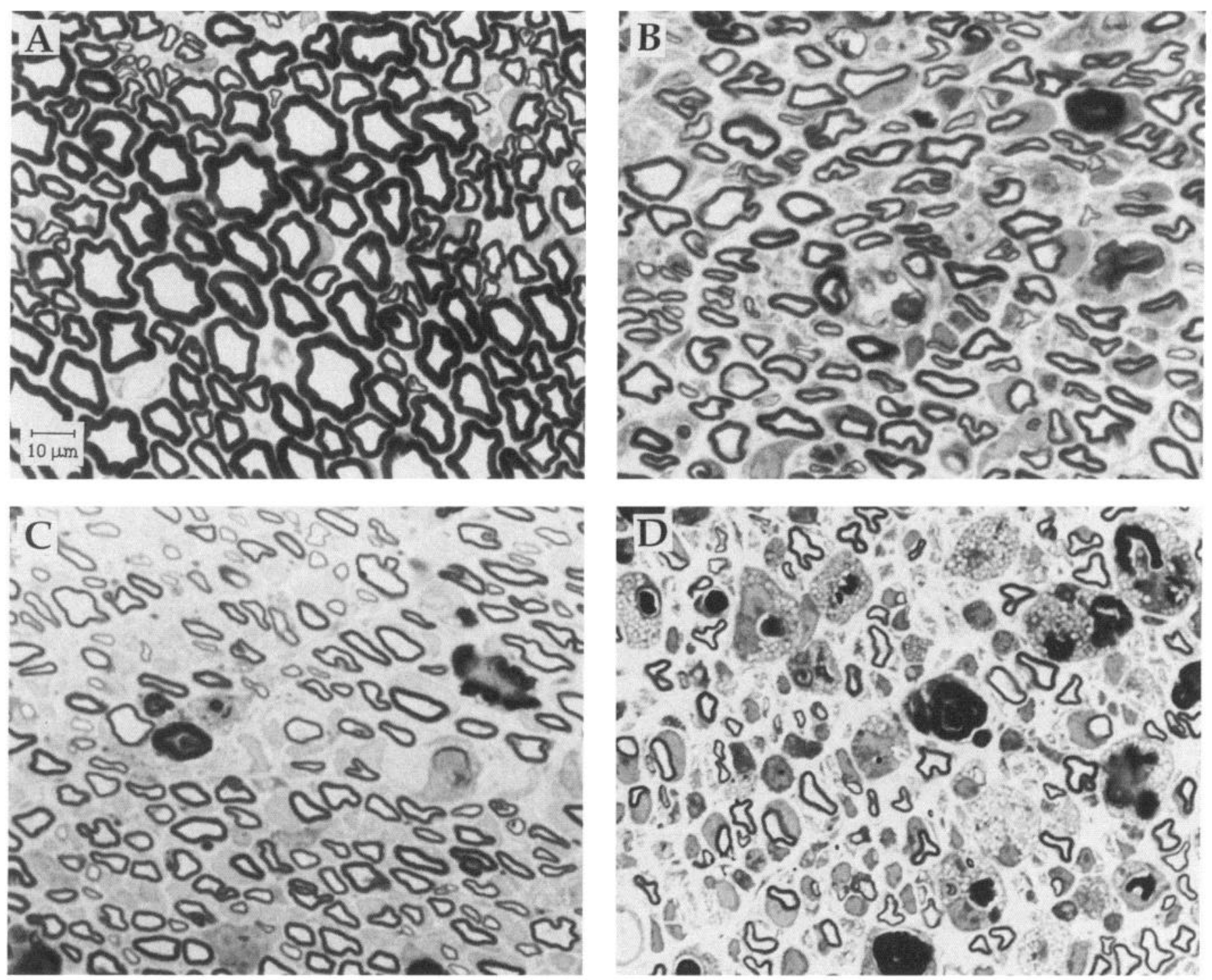

Figure 2. Light microscopic $28 \mathrm{~d}$ crush morphology. Light microscopic views of sciatic nerves in 10-14-week-old mice. The scale bar in the lower left corner of $A$ applies to all panels in this figure. $A$, Uninjured $+/+$ sciatic nerve. $B, 3 \mathrm{~mm}$ distal to crush site within the sciatic nerve of a $+1+$ mouse $28 \mathrm{~d}$ after receiving a crush injury. $C$, $+/ E n r$ sciatic nerve $28 \mathrm{~d}$ after receiving a crush injury. $D$, An Enr/Enr crush-injured nerve $28 \mathrm{~d}$ after injury.

environment with Enr/Enr SCs, regeneration is severely impaired (Fig. $6 E$ ). Regeneration does not improve when these + / + axons pass through the graft and into the $+/+\mathrm{SC}$ environment distal to the graft (Fig. $6 J$ ).

Wild type nerve segments were grafted into $+/ E n r$ animals (Fig. $6 B, G$ ), and $+/ E n r$ nerves were also grafted into $+/+$ animals (Fig. $6 D, I$ ). The appearance within these grafts follows the pattern of regeneration outlined above. That is, whenever $+/+$, $+/ E n r$, or Enr/Enr axons encounter $+/+$ SCs (Fig. 6A, B, or $C)$, regeneration progresses well, except when regeneration is difficult through the graft (as in Fig. $6 D, E$ ), then it continues to be poor distally (Fig. $6 I, J$ ). Whenever $+/+$ axons encounter a grafted environment of Enr/Enr or $+/ E n r$ SCs, regeneration is poor within the graft (Fig. $6 D, E$ ). After $+/ E n r$ or Enr/Enr axons regenerate well through $+1+$ grafts (Fig. $6 B, C$ ), impaired regeneration within the distal endogenous nerve is again observed (Fig. 6G,H). Together, the graft experiments strongly suggest that the Enr mutation does not confer an intrinsic defect in neurons. Rather, these studies indicate that the impaired regenerative response is due to a less suitable environment in the distal stumps of Enr nerves.

\section{Temporal patterns of gene expression in sciatic nerve regeneration}

In order to examine if the morphological differences in regeneration between $E n r / E n r$ and $+/+$ mice are related to altered gene expression, we examined the steady state mRNA levels for a number of genes known to be differentially expressed in a spatiotemporal manner after peripheral nerve injury. Levels of mRNA for NGFr, GFAP, and suppressed cAMP-inducible POU (SCIP) were used to probe Schwann cells and their state of differentiation. NGFr is a molecular marker for the entire population of dedifferentiated SCs distal to the site of peripheral nerve injury, and its mRNA expression is dramatically increased when axons lose contact with SCs (Taniuchi et al., 1986; Taniuchi et al., 1988). GFAP is a marker for nonmyelinating SCs (Gould et al., 1992) and its expression increases during Wallerian degeneration (Thomson et al., 1993) and during demyelination (Toews 

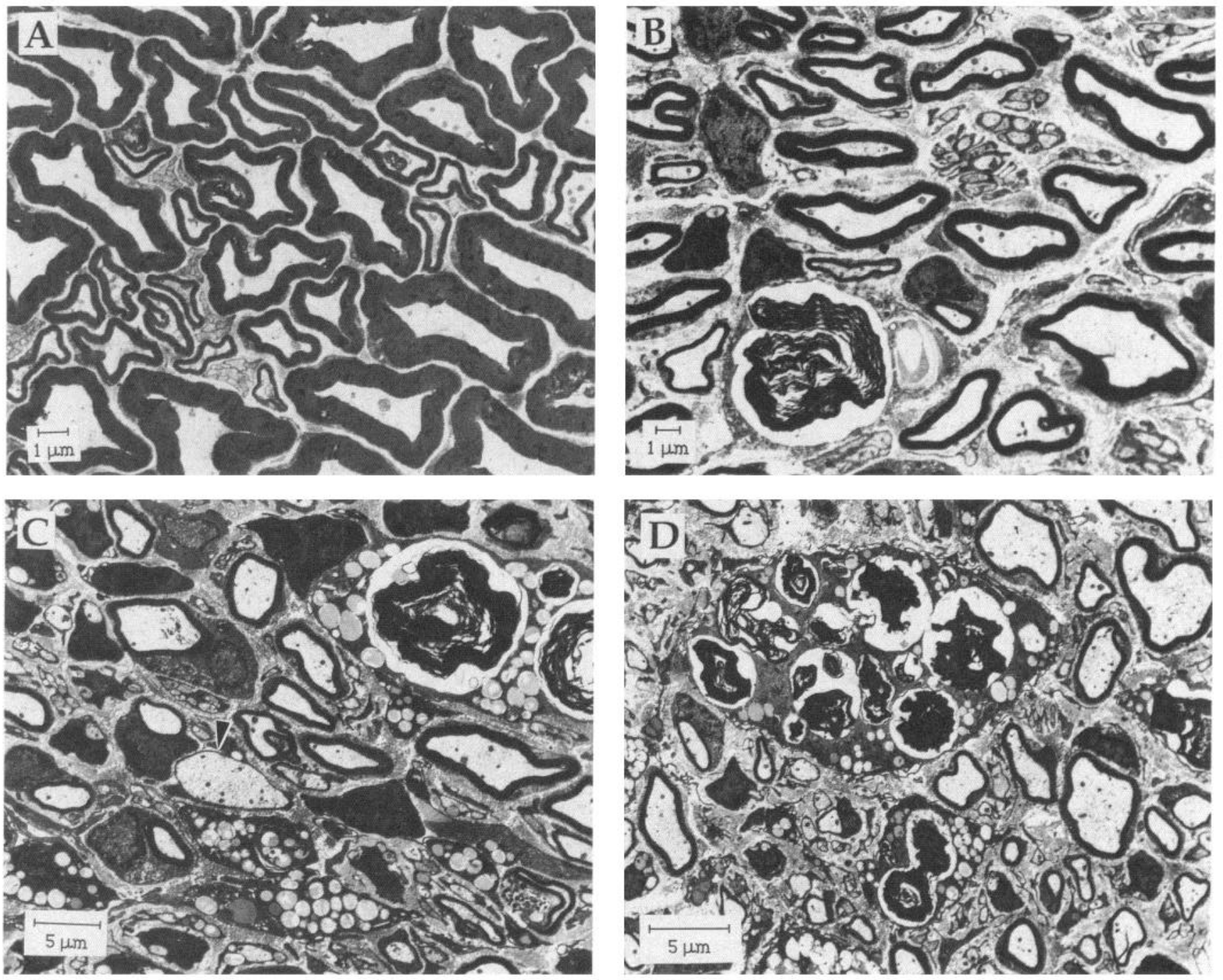

Figure 3. Electron microscopic $28 \mathrm{~d}$ crush morphology. Ultrastructure of crushed sciatic nerves in 10-14 weekold mice. Scale bars for each panel shown in the lower left corner. $A$, Uninjured $+/+$ sciatic nerve. $B .+1+$ mouse $28 \mathrm{~d}$ after injury. $C$ and $D, E n r / E n r$ sciatic nerves $28 \mathrm{~d}$ after crush. $C$, Arrowhead denotes large diameter unmyelinated axon.

et al., 1992). SCIP is a POU domain transcription factor expressed by SCs, with expression regulated by axonal contact (Scherer et al., 1994). SCIP is expressed during the proliferative state that precedes SC myelination, and may function to regulate the proliferative transitional state of SCs from the premyelinating to myelinating phenotype (Monuki et al., 1990). The mRNA levels of lysozyme and apolipoprotein $\mathrm{E}(\mathrm{ApoE})$ were also examined to evaluate macrophage presence and activity. Figure 7 shows wild type and Enr/Enr mRNA expression patterns at 7 and $28 \mathrm{~d}$ after crush injury to sciatic nerves. A difference in GFAP mRNA levels is noted at $7 \mathrm{~d}$ after crush, with decreased expression (11-fold less) seen in the Enr/Enr nerves. GFAP mRNA levels appear similar for both groups at $28 \mathrm{~d}$. In contrast, NGFr, SCIP, lysozyme, and ApoE steady state mRNA levels appear similar for the two groups at $7 \mathrm{~d}$, but remain up regulated at $28 \mathrm{~d}$ in Enr/Enr mice compared to $+/+$ mice (NGFr and SCIP are sixfold higher, lysozyme and ApoE are twofold higher). The pattern of expression for the Schwann cell adhesion molecule L1 is similar to the pattern of expression observed with NGFr (data not shown). The mRNA levels of the peripheral myelin protein, $\mathrm{P}_{0}$, appear similar in both genotypes at both time periods (data not shown). No differences in gene expression between $E n r / E n r$ and $+1+$ uninjured nerves were noted (data not shown).

\section{Discussion}

Homozygous Enr mice exhibit neuropathologic features characteristic of disrupted SC-axon interactions. Crush injury to Enr/ Enr and +/Enr peripheral nerves leads to Wallerian degeneration followed by impaired regeneration. The peripheral neuropathy, impaired regeneration, and results from nerve grafting studies, taken together, suggest that the disrupted SC-axon interactions and impaired regeneration are associated primarily with a SC defect. Moreover, Northern blot analysis suggests a potential defect in SC differentiation.

Peripheral neuropathy characteristic of a defect in Schwann cell-axon interactions

In uninjured Enr/Enr peripheral nerves there are a variety of neuropathic features consistent with a defect in SC-axon inter- 
Table 1. Morphometric and statistical analyses of uninjured control and crush-injured sciatic nerves

\begin{tabular}{lrrrl} 
& $\begin{array}{c}\text { Wild } \\
\text { type }\end{array}$ & $\begin{array}{r}\text { Hetero- } \\
\text { zygous }\end{array}$ & $\begin{array}{c}\text { Homo- } \\
\text { zygous }\end{array}$ \\
\hline Control & & & & \\
A. Axons per $\mathrm{mm}^{2}$ & 30.85 & 31.26 & 29.40 & n.s. \\
B. Fiber diameter & 5.66 & 5.67 & 5.72 & n.s. \\
C. Axon diameter & 4.09 & 4.07 & 4.26 & n.s. \\
D. Myelin thick. & 0.78 & 0.80 & 0.73 & n.s. \\
E. \% Myelin & 42.87 & 45.20 & 38.35 & $p<0.05$ \\
F. \% Axon & 48.20 & 48.33 & 49.58 & n.s. \\
G. \% m + a & 91.07 & 93.53 & 87.93 & n.s.
\end{tabular}

Crush

$\begin{array}{lrrrl}\text { A. Axons per } \mathrm{mm}^{2} & 30.56 & 25.36 & 19.70 & p<0.05 \\ \text { B. Fiber diameter } & 4.36 & 4.46 & 3.92 & p<0.05 \\ \text { C. Axon diameter } & 3.09 & 3.22 & 2.91 & \text { n.s. } \\ \text { D. Myelin thick. } & 0.63 & 0.62 & 0.49 & p<0.05 \\ \text { E. \% Myelin } & 26.96 & 20.39 & 11.29 & p<0.01 \\ \text { F. \% Axon } & 24.00 & 24.65 & 15.56 & p<0.05 \\ \text { G. \% m }+ \text { a } & 50.96 & 45.04 & 26.85 & p<0.01\end{array}$

The number of nerves evaluated, the number of images processed from these nerves, and the total number of myelinated axons counted for $+/ t,+/ E n r$ and Enr/Enr genotypes in either the control or injured paradigm are as follows. Control: $+1+(3,49,3175),+/ \operatorname{Enr}(3,37,2429)$, Enr/Enr $(3,41,2530)$; Crush: $+1+(3,43,2760),+/ \operatorname{Enr}(4,54,2876)$, EnrlEnr $(3,61,2532)$. All nerve sections evaluated in the crush-injured paradigm are from sciatic nerves $28 \mathrm{~d}$ after injury, $-3 \mathrm{~mm}$ distal to the crush site. Control sections were taken from contralateral uninjured nerves at a similar anatomic location as crush-injured sections. The parameters evaluated include $A$, the mean number of myelinated axons per $\mathrm{mm}^{2} ; \mathrm{B}$, the mean myelinated fiber diameter $(\mu \mathrm{m}) ; \mathrm{C}$, the mean axon diameter $(\mu \mathrm{m}) ; \mathrm{D}$, the mean myelin thickness around each axon $(\mu \mathrm{m}) ; \mathrm{E}$, the mean \% image area occupied by myelin associated with axons (not including myelin debris); $F$, the mean $\%$ image area occupied by axon; and $G$, the mean $\%$ image area occupied by myelin and axon summed from $F$ and $G$. Statistical analysis by single factor ANOVA. Statistical significance simultaneously comparing the three genotypes is listed to the right of each row. n.s., nonsignificant.

actions. In addition to bundles of bare, juxtaposed, small diameter unmyelinated axons (Kelly et al., 1994), there are bundles of relatively large diameter unmyelinated axons without complete SC cnshcathment. Also present are independent large diameter unmyelinated axons that are of sufficient size to be myelinated. Moreover, there are bundles of small diameter axons enclosed within a single myelin sheath.

Many of these findings have been reported in dystrophic $(d y)$ mice where deficient SC function in producing basal lamina is linked with an abnormality in SC-axon interactions (Bradley and Jenkison, 1975; Okada et al., 1977; Jaros and Bradley, 1978, 1979). Recently, a laminin isoform, merosin, has been reported to be primarily deficient in the peripheral nerves of $d y$ mice (Sunada et al., 1994). Yamada et al. (1994) suggest that the $d y$ defect may alter SC differentiation and myelination. Similarly, when in vitro basal lamina formation is perturbed, SCs fail to ensheath and myelinate axons (Bunge et al., 1990), apparently the result of a defect in differentiation of axon-related SCs. We did not observe a basal lamina defect in Enr/Enr mice.

\section{Impaired peripheral nerve regeneration}

Crush injuries to peripheral nerves in Enr/Enr and $+/ E n r$ mice results in diminished peripheral nerve regeneration up to 8 weeks after injury (the latest time point evaluated). Both sensory and motor nerves seem equally affected in their impaired ability to regenerate. Morphometric data reveal significantly fewer my-

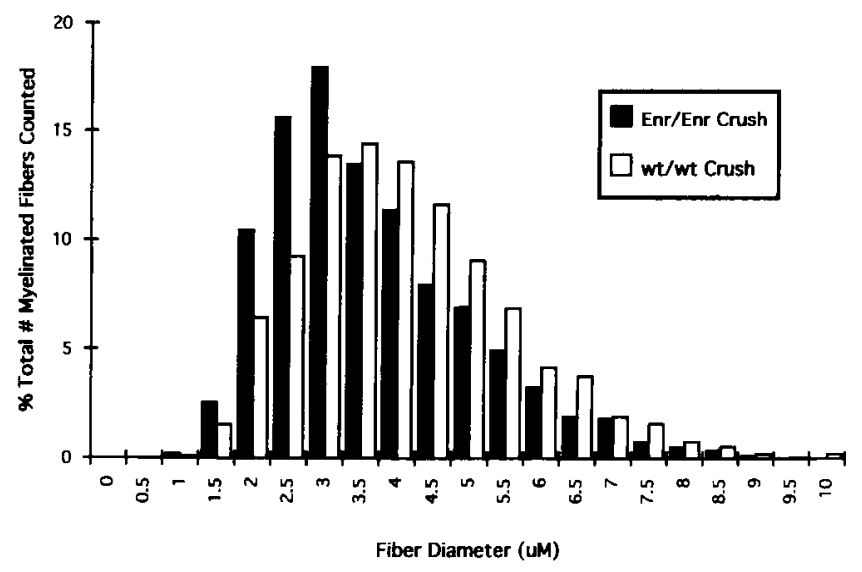

Figure 4. Fiber diameter histogram: homozygous versus wild type. The percentage of the total number of myelinated fibers counted that fall within each $0.5 \mu \mathrm{M}$ bin for either homozygous or wild type (wt/wt) nerves at $28 \mathrm{~d}$ after crush injury ( $E n r / E n r$ total $n=2532$; wt/wt total $n=2760$ ).

elinated axons per $\mathrm{mm}^{2}$ in the Enr/Enr crushed sciatic nerves four weeks after injury. While the number of myelinated axons per $\mathrm{mm}^{2}$ in the $+/+$ crushed nerves approaches uninjured values, the number of myelinated axons in Enr/Enr crushed nerves is reduced by approximately $35 \%$ compared to Enr/Enr uninjured nerves or to the $+/+$ crushed nerves. There is also a $23 \%$ reduction in the myelin thickness around regenerating axons in the Enr/Enr nerves compared to the $+/+$ nerves, but only a $6 \%$ reduction in Enr/Enr axon diameter. Proportionately, there is a larger than expected reduction in myelin thickness in regenerating Enr/Enr crushed nerves.

SC-axon disruptions remain after injury to peripheral nerves in $E n r / E n r$ mice. Unmyelinated large diameter axons appear frequently in regenerating Enr/Enr nerves, and are not seen in regenerating $+/+$ nerves. There is also more debris in Enr/Enr crushed nerves. It may be that regenerating $E n r / E n r$ axons are impeded on their path through the distal stump by debris-filled endoneurial tubes. The Enr/Enr mouse is distinct from the Wlds (ola) mouse in which myelinated axons distal to an injury site remain intact for up to $10 \mathrm{~d}$ due to a primary axon defect (Griffin and Hoffman, 1993). The slow degeneration observed in Wld animals also results in regenerating axons encountering an environment lacking a source of proliferating, dedifferentiated SCs (Lunn et al., 1989), and this too is thought to impede regeneration. At seven days after injury, however, both Enr/Enr and + I + crushed nerves show similar morphological pattcrns of degeneration and early regeneration.

\section{Nerve graft studies suggest a primary Schwann cell defect}

The primary defect of impaired regeneration in Enr/Enr mice appears to be SC associated, and not a primary neural or macrophage defect. Wild type axons appear to be fewer and less well myelinated in Enr/Enr and +/Enr grafted segments, whereas regeneration of $+/+,+/ E n r$, and Enr/Enr axons within $+/+$ grafted segments appears normal. These results discount a primary neural defect. Furthermore, if there were a primary defect in Enr macrophages, one would expect wild type macrophages to invade the $+/ E n r$ and Enr/Enr grafted segments in $+/+$ mice and contribute to a normal regenerative response. We did not observe wild type-like regenerative efforts in the Enr/Enr grafts. It is interesting to note that regeneration does not improve when 

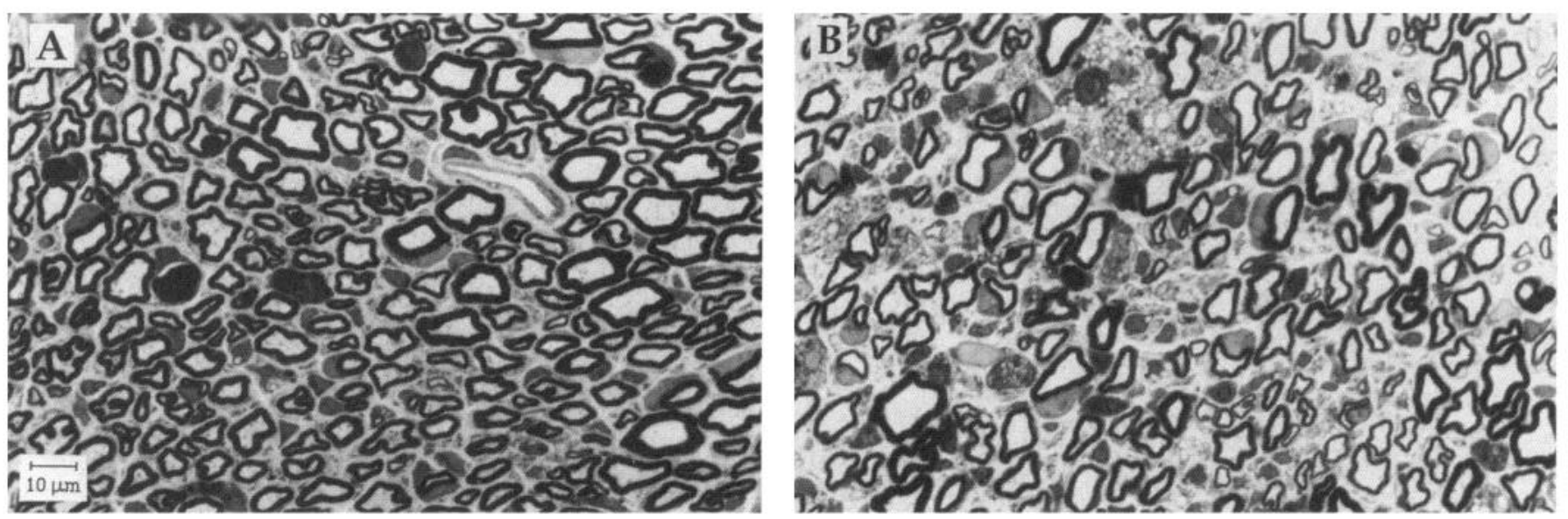

Figure 5. Light microscopic eight week crush morphology. Light microscopic views of wild type $(A)$ or mutant homozygous $(B)$ sciatic nerves 8 weeks after crush injury. $A$ and $B$ represent sections taken approximately $3 \mathrm{~mm}$ distal to the crush site. The scale bar in the lower left of $A$ applies to both panels.

$+/+$ axons pass through an Enr/Enr graft and again reach an endogenous environment. Perhaps $+I+$ nerve fibers encounter an environment nonconducive to regeneration in the Enr/Enr grafted segment, so that few axons can regenerate through the graft, and those that do are poorly supported by Enr/Enr SCs along the length of the Enr/Enr graft.

\section{Gene expression in Enr crushed nerves}

The expression of GFAP, which in the peripheral nerve is a marker for nonmyelinating SCs (Gould et al., 1992), increases during Wallerian degeneration (Thomson et al., 1993) and during demyelination (Toews et al., 1992). At $7 \mathrm{~d}$ after crush injury there is 11-fold less GFAP mRNA in the Enr/Enr crushed nerves compared to $+/+$ crushed nerves. At 28 d after injury, GFAP mRNA levels appear similar in Enr/Enr and $+/+$ mice. NGFr is a molecular marker for the entire population of dedifferentiated SCs distal to the site of peripheral nerve injury, and its mRNA expression is dramatically increased when axons lose contact with SCs (Taniuchi et al., 1986; Taniuchi et al., 1988), and downregulated as regenerating axons pass through endoneurial tubes toward their target tissue (Heumann et al., 1987). At $7 \mathrm{~d}$ after crush injury we see similar steady state levels of NGFr mRNA in wild type and Enr/Enr mice, whereas NGFr mRNA levels remain substantially higher in Enr/Enr nerves at $28 \mathrm{~d}$, and do not return to near baseline levels as seen in $+1+$ crushed nerves. SCIP is a POU domain transcription factor expressed by SCs during the proliferative state that precedes SC myelination, and may function to regulate the transitional state of SCs from the premyelinating to myelinating phenotype (Monuki, et al., 1990). Compared to $+/+$ crushed nerves at $28 \mathrm{~d}$, Enr/Enr crushed nerves show sixfold higher levels of SCIP expression, indicating an increased number of SCs in transition. This may suggest that Enr/Enr axons have regenerated slower, resulting in delayed myelination, whereas $+/+$ nerves may advance past this stage earlier as indicated by downregulation of SCIP mRNA levels at $28 \mathrm{~d}$. While Scherer et al. (1994) continue to see an increase in SCIP expression at $58 \mathrm{~d}$ after peripheral nerve crush injury in the rat, we observe downregulation of SCIP mRNA levels in the normal mouse by $28 \mathrm{~d}$ after nerve injury. Perhaps species variation accounts for these differences and normal mouse SCs mature and the nerve regenerates at a relatively faster rate.
Both SCs and macrophages are important in myelin phagocytosis and debris removal and in the nerve's reparative response to injury (Bigbee et al., 1987; Heumann et al., 1987; Brown et al., 1991; Goodrum et al., 1994; Reichert et al., 1994). The twofold increased levels of mRNA for both lysozyme and ApoE in the crushed nerves of Enr/Enr mice at $28 \mathrm{~d}$ suggest an ongoing macrophage-mediated phagocytic, cholesterol/lipid reutilization process (Venezie et al., 1995) greater than that seen in $+1+$ mice. This is consistent with the morphological data we have observed in which there appears to be increased levels of lipid droplets and myelin debris in the $28 \mathrm{~d}$ crushed nerves of homozygous mutant mice.

\section{Is impaired regeneration due to a defect in Schwann cell differentiation?}

SCs have the ability to respond to a complex pattern and number of mitogens derived from sources intimately associated with peripheral nerve (DeVries, 1993). The Enr phenotype could be due to a primary defect in SC proliferation, such that there is a decrease in the absolute numbers of SCs to sort and ensheath or myelinate axons. If the absolute numbers of nonmyelinating and myelinating SCs are slowly achieved because of impaired early SC proliferation, then the regenerative response that normally takes place in peripheral nerve may be limited. Nevertheless, the mRNA levels of NGFr at $7 \mathrm{~d}$ after crush are similar in both wild type and Enr/Enr mice, suggesting relatively normal levels of dedifferentiated Enr/Enr SCs. In addition, preliminary immunohistochemical data suggests that the number of $\mathrm{S} 100$ positive cells present in Enr/Enr nerves following injury is comparable to wild type nerves (Rath and Popko, unpublished observations).

As mentioned, at E16 SCs are NGFr positive and GFAP negative. By E18 the "early" SCs have differentiated to a more mature O4 and GFAP positive "bipotential" phenotype (Fig. 8) (Jessen and Mirsky, 1991). After injury to a peripheral nerve, SCs become NGFr positive and remain $\mathrm{S} 100$ positive but are initially $\mathrm{O} 4$ negative, suggesting a reversion of SCs to the phenotype observed on embryonic days 16-17. This is a developmental period prior to the differentiation of cells to a GFAP positive phenotype (Fig. 8). The normal levels of NGFr mRNA seen in the Enr/Enr mice at $7 \mathrm{~d}$ after nerve injury suggest that the dedifferentiation of SCs to an "early" SC phenotype is occurring typically. Nevertheless, at $7 \mathrm{~d}$ after crush, GFAP mRNA 


\section{Within Graft}

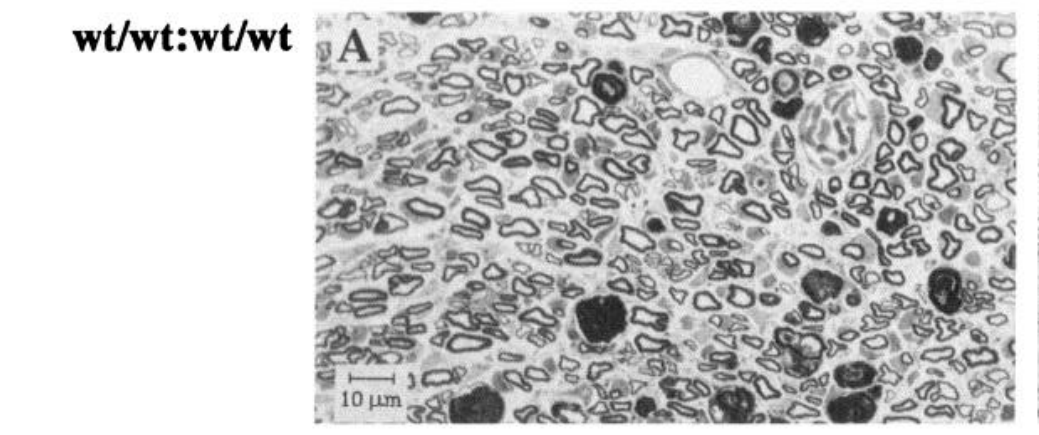

\author{
wt/wt:wt/Enr
}
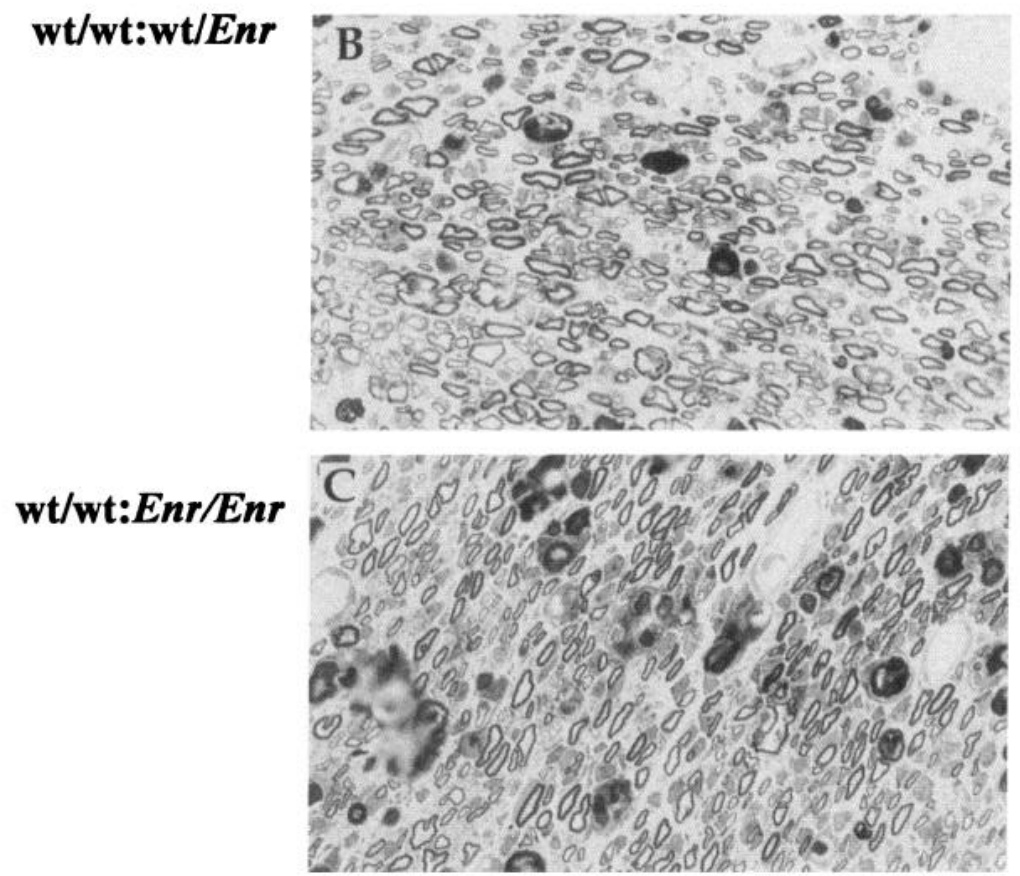

wt/Enr:wt/wt

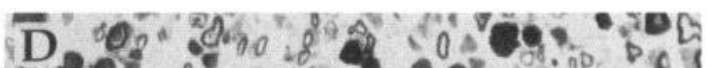

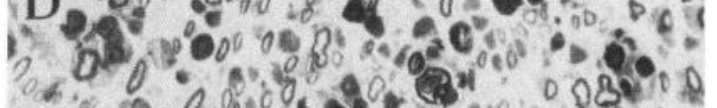

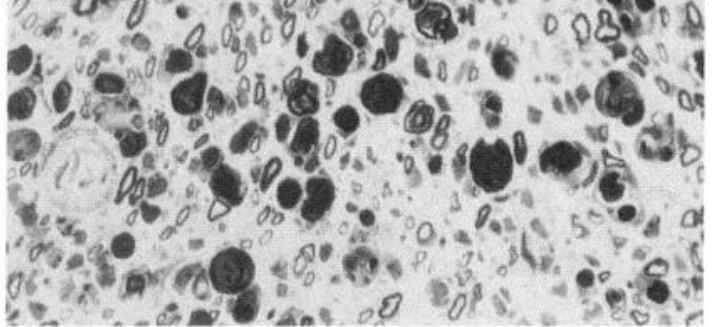

Enr/Enr:wt/wt

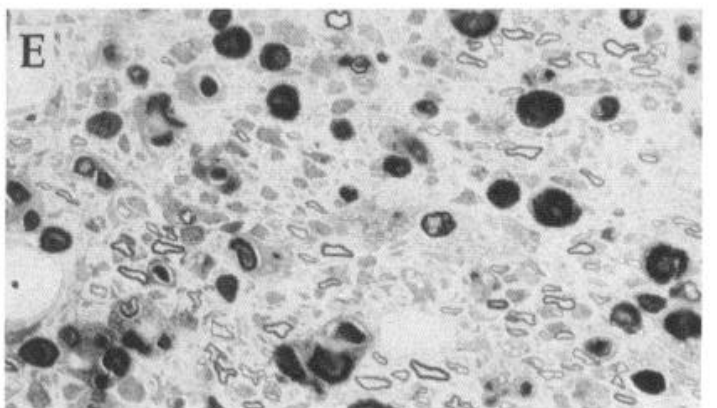

\section{Distal to Graft}
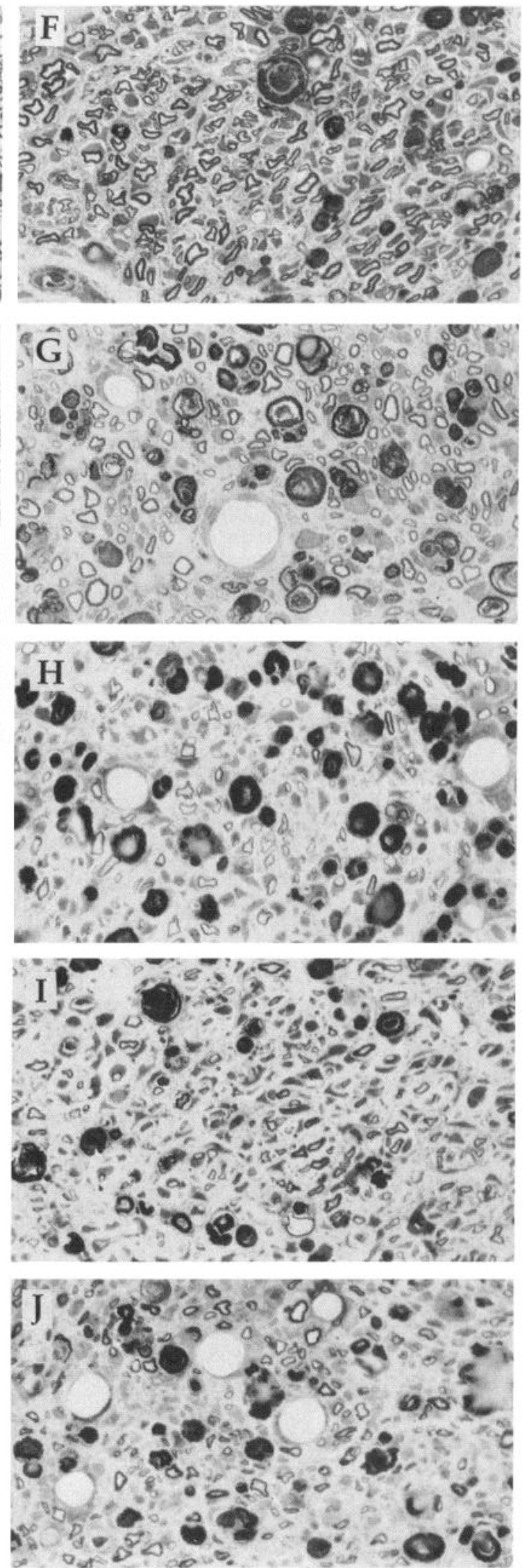

Figure 6. Nerve grafts. Light microscopic view of sciatic nerves within the middle of a $7 \mathrm{~mm}$ grafted segment $(A-E)$ or $3 \mathrm{~mm}$ distal to the grafted segment $(F-J) 28 \mathrm{~d}$ after transplantation. Donor and recipient genotypes (donor:recipient) are listed to the left of each pair of sections. The scale bar in the lower left of $A$ applies to all panels (wt/wt $=$ wild type, wV $/ E n r=$ heterozygous, Enr/Enr $=$ homozygous). 


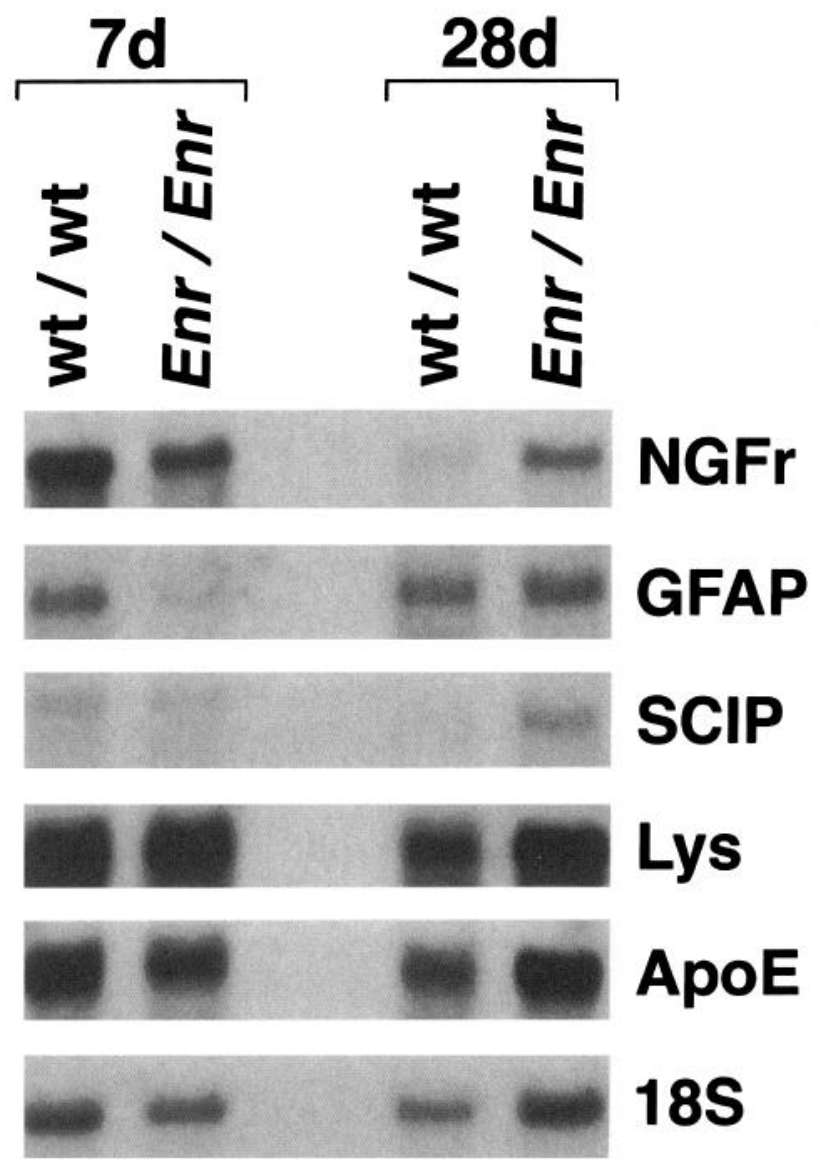

Figure 7. Northern blot analysis. mRNA levels at either 7 or $28 \mathrm{~d}$ after crush injury in wild type (wt/wt) or homozygous $(E n r / E n r)$ mice. Total sciatic nerve RNA pooled from five nerves in each group at each time point. Signal intensities on autoradiographs were quantitated (MCID Ml system, Imaging Research Inc., St. Catherines, Ontario, Canada), with reference to the relative amount of total RNA in each lane (18S bands), and reveal an 11-fold reduction in GFAP mRNA in Enr/Enr nerves at $7 \mathrm{~d}$ compared to $\mathrm{wt} / \mathrm{wt}$ nerves. In homozygous nerves at $28 \mathrm{~d}$ after crush there is a sixfold increase in NGFr and SCIP mRNA levels, and a twofold increase in lysozyme (Lys) and ApoE. Levels of mRNA for NGFr, SCIP, lysozyme, and ApoE at seven days, and GFAP at $28 \mathrm{~d}$, are similar between the two groups. A single northern blot was probed multiple times for the results shown and described above.

levels in the Enr/Enr mice are 11-fold less than normal. The differences in mRNA levels between GFAP and NGFr, in $+/+$ compared to Enr/Enr mice (Fig. 7), suggest a defect in the ability of Enr/Enr "early" SCs to differentiate into a "bipotential" phenotype (Fig. 8).

The differentiated state of the SC and the time course of differentiation are important in peripheral nerve development (Stewart et al., 1993) and in regeneration after injury (Zhao and Kerns, 1994). If the dedifferentiated early SCs are present and remain immature longer than normal, they may be unable to ensheath or myelinate in a normal temporal manner (Perkins et al., 1991). Temporally delayed SC differentiation could lead to a slow start in regeneration and may relate to the disproportional decrease in myelin thickness surrounding Enr/Enr axons. Moreover, the regenerative response may be prolonged and impaired, as suggested by increased NGFr, SCIP, and lysozyme mRNA levels at $28 \mathrm{~d}$ after injury. Ultimately, because of this and other abnormalities in regenerating $E n r$ nerves (e.g., excess debris, improper 1:1 SC-axon relations), Enr/Enr neurons may be de-

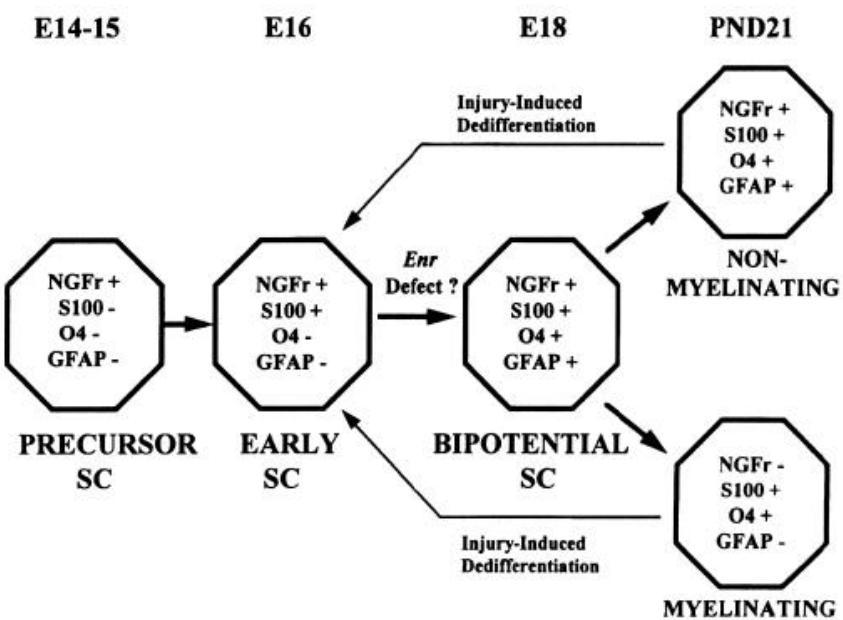

Figure 8. Schematic diagram of Schwann cell development and model for Enr defect. Adapted from Jessen and Mirsky (1991). The molecular phenotype for Schwann cells is shown for each stage of differentiation during development. Embryonic day 14-15 (E14-15) Schwann cells are designated as "precursor" SCs. E16-17 Schwann cells are denoted as "early" SCs. E18 Schwann cells are classified as "bipotential" SCs that will differentiate to a nonmyelinating or myelinating phenotype by postnatal day 21 (PND21). Injury to a peripheral nerve results in dedifferentiation of Schwann cells to an "early" E16-17 SC molecular phenotype. We postulate the Enr defect to be in the ability of "early" SCs to properly differentiate into "bipotential" SCs during development and regeneration.

prived of normal SC-derived support for a sufficiently long period to lead to increased neuron death (Varon and Bunge, 1978, Politis et al., 1982, Blottner and Baumgarten, 1994).

In summary, it appears that the Enr mutation has affected a vital regulatory component in SC-axon interactions, which is especially evident after nerve injury. Peripheral nerve regeneration, while resembling peripheral nerve development, may not be an accurate recapitulation of the normal developmental events. Neurons and SCs may have different requirements in the two distinct settings. A SC defect in differentiating from an "early" precursor phenotype to a more mature SC phenotype, however, might contribute to both the impaired regeneration and the peripheral neuropathy in uninjured nerves seen in Enr/Enr mice. Isolation and characterization of the disrupted gene will be helpful in better analyzing this possibility, and in clarifying the responsible mechanism. Previously, we have physically mapped the transgene in these mice, which has insertionally disrupted the function of an endogenous gene, to the B4-B5 region of mouse chromosome 11 (Kelly et al., 1994) which contains a number of genes expressed by Schwann cells that are believed to be important in peripheral nerve regeneration. GFAP, NGFr, and $e r b \mathrm{~B} 2$, which encodes a component of the glial growth factor receptor and is up regulated following peripheral nerve injury (Cohen et al., 1992), all map to the vicinity of the transgene (Buchberg and Camper, 1993). Nevertheless, a preliminary analysis has not revealed any physical alterations of these genes in Enr animals. We are presently examining other candidate genes in the region as well as using the transgene as a molecular tag in an effort to identify the Enr gene.

\section{Note added in proof:}

The enervated (Enr) mice described here are available from the Mouse Mutant Resource at the Jackson Laboratory, Bar Harbor, Maine. 


\section{References}

Aguayo AJ, Bray GM, Perkins SC (1979) Axon-Schwann cell relationships in neuropathies of mutant mice. Ann NY Acad Sci 317: 512-531.

Auer RN (1994) Automated nerve fibre size and myelin sheath measurement using microcomputer-based digital image analysis: theory, method, and results. J Neurosci Methods 51:229-238.

Beuche W, Friede RL (1984) Naked axon bundles enclosed by single segments of myelin sheaths in the nerves of non-dystrophic C57BLob/+mice. Neuropathol Appl Neurobiol 10:369-377.

Bigbee JW, Yoshino JE, DeVries GH (1987) Morphological and proliferative responses of cultured Schwann cells following rapid phagocytosis of a myelin enriched fraction. J Neurocytol 16:487-496.

Blottner D, Baumgarten HG (1994) Neurotrophy and regeneration in vivo. Acta Anat 150:235-245.

Bradley WG, Jenkison M (1975) Neural abnormalities in the dystrophic mouse. J Neurol Sci 25:249-255.

Bray GM, Rasminsky M, Aquayo AJ (1981) Interactions between axons and their Schwann cells. Annu Rev Neurosci 4:127-162.

Brown MC, Perry VH, Lunn ER, Gordon S, Heumann R (1991) Macrophage dependence of peripheral sensory nerve regeneration: possible involvement of nerve growth factor. Neuron 6:359-370.

Buchberg AM, Camper SA (1993) Mouse chromosomc 11. Mammalian Genome 4:S164-S175.

Bunge MB (1993) Schwann cell regulation of extracellular matrix biosynthesis and assembly. In: Peripheral neuropathy, 3d ed (Dyck PJ, Thomas PK, Griffin JW, Low PA, Poduslo JP, eds), pp 299-316. Philadelphia: Saunders.

Bunge RP (1993) Expanding roles for the Schwann cell: ensheathment, myelination, trophism, and regeneration. Curr Opin Neurobiol 3:805809.

Bunge MB, Clark MB, Dean AC, Eldridge CF, Bunge RP (1990) Schwann cell function depends upon axonal signals and basal lamina components. Ann NY Acad Sci 580:281-287.

Chirgwin JM, Przybyla AE, MacDonald RJ, Rutter WJ (1979) Isolation of biologically active ribonucleic acid from sources enriched in ribonuclease. Biochemistry 18:5294-5299.

Cohen JA, Yachnis AT, Arai M, Davis JG, Scherer SS (1992) Expression of the neu proto-oncogene by Schwann cells during peripheral nerve development and Wallerian degeneration. J Neurosci Res 31 : 622-634.

Cross M, Mangelsdorf I, Wedel A, Renkawitz R (1988) Mouse lysozyme $\mathrm{M}$ gene isolation, characterization, and expression studies. Proc Natl Acad Sci USA 85:6232-6236.

DeVries GH (1993) Schwann cell proliferation. In: Peripheral neuropathy, 3d ed (Dyck PJ, Thomas PK, Griffin JW, Low PA, Poduslo JP, eds), pp 290-298. Philadelphia: Saunders.

deWaegh SM, Lee VM-Y, Brady ST (1992) Local modulation of neurofilament phosphorylation, axonal caliber, and slow axonal transport by myelinating Schwann cells. Cell $68: 451-463$.

Fawcett JW, Keynes RJ (1990) Peripheral nerve regeneration. Annu Rev Neurosci 13:43-60.

Feinberg A, Volgelstein B (1983) A technique for radiolabeling DNA restriction endonuclease fragments to high specificity. Anal Biochem 132:6-13

Goodrum JF, Earnhardt T, Goines N, Bouldin TW (1994) Fate of myelin lipids during degeneration and regeneration of peripheral nerve: an autoradiographic study. J Neurosci 14:357-367.

Gould RM, Jessen KR, Mirsky R, Tennekoon G (1992) The cell of Schwann: an update. In Myelin: biology and chemistry (Martenson RE, ed), pp 123-171. Ann Arbor, MI: CRC.

Griffin JW, Hoffman PN (1993) Degeneration and regeneration in the peripheral nervous system. In: Peripheral neuropathy, 3d ed (Dyck PJ, Thomas PK, Griffin JW, Low PA, Poduslo JP, eds), pp 361-376. Philadelphia: Saunders.

Griffin JW, Kidd G, Trapp BD (1993) Interactions between axons and Schwann cells. In: Peripheral neuropathy, 3d ed (Dyck PJ, Thomas PK, Griffin JW, Low PA, Poduslo JP, eds), pp 317-330. Philadelphia: Saunders

Hall SM (1986) The effect of inhibiting Schwann cell mitosis on the re-innervation of acellular autografts in the peripheral nervous system of the mouse. Neuropathol Appl Neurobiol 12:401-414.

Heumann R. Lindholm D, Bandtlow C, Meyer M, Radeke MJ, Misko TP, Shooter E, Thoenen H (1987) Differential regulation of mRNA encoding nerve growth factor and its receptor in rat sciatic nerve during development, degeneration, and regeneration: role of macrophages. Proc Natl Acad Sci USA 84:8735-8739.

Jansen R, Ledley FD (1989) Production of discrete high specific activity DNA probes using the polymerase chain reaction. Genet Anal Tech Appl 6:79-83.

Jaros E, Bradley WG (1978) Development of the amyelinated lesion in the ventral root of the dystrophic mouse: ultrastructural, quantitative, and autoradiographic study. J Neurol Sci 36:317-339.

Jaros E, Bradley WG (1979) Atypical axon-Schwann cell relationships in the common peroneal nerve of the dystrophic mouse: an ultrastructural study. Neuropathol Appl Neurobiol 5:133-147.

Jessen KR, Mirsky R (1991) Schwann cell precursors and their development. Glia 4:185-194.

Jessen KR, Morgan L, Stewart HJS, Mirsky R (1990) Three markers of adult non-myclin-forming Schwann cells, 217c(Ran-1), A5E3, and GFAP: development and regulation by neuron-Schwann cell interactions. Development 109:91-103.

Johnson EM, Taniuchi M, DiStefano PS (1988) Expression and possible function of nerve growth factor receptors on Schwann cells Trends Neurosci 11:299-304.

Kelly D, Chancellor K, Milatovich A, Francke U, Suzuki K, Popko B (1994) Autosomal recessive neuromuscular disorder in a transgenic line of mice. I Neurosci 14:198-207.

Lewis SA, Balcarek JM, Krek V, Shelanski M, Cowan NJ (1984) Sequence of a cDNA clone encoding mouse glial fibrillary acidic protein: structural conservation of intermediate filaments. Proc Natl Acad Sci USA 81:2743-2746.

Lunn ER, Perry VH, Brown MC, Rosen H, Gordon S (1989) Absence of Wallerian degeneration does not hinder regeneration in peripheral nerve. Eur J Neurosci 1:27-33.

Martini R (1994) Expression and functional roles of neural cell surface molecules and extracellular matrix components during development and regeneration of peripheral nerves. J Neurocytol $23: 1-28$.

McLean JW, Fukazawa C, Taylor JM (1983) Rat apolipoprotein E mRNA. J Biol Chem 258:8993-9000.

Mezei C (1993) Myelination in the peripheral nerve during development. In: Peripheral neuropathy, 3d ed (Dyck PJ, Thomas PK, Griffin JW, Low PA, Poduslo JP, eds), pp 267-281. Philadelphia: Saunders.

Monuki ES, Weinmaster G, Kuhn R, Lemke G (1989) SCIP: a glial POU domain gene regulated by cyclic AMP. Neuron 3:783-793.

Monuki ES, Kuhn R, Weinmaster G, Trapp BD, Lemke G (1990) Expression and activity of the POU transcription factor SCIP. Science 249:1300-1303.

Okada E, Mizuhira V, Nakamura H (1977) Abnormally combined myelinated and unmyelinated nerves in dystrophic mice. J Neurol Sci 33:243-249.

Perkins CS, Bray GM, Aquayo AJ (1981) Ongoing block of Schwann cell differentiation and deployment in dystrophic mouse spinal roots. Dev Brain Res 1:213-220.

Politis MJ, Ederle K, Spencer PS (1982) Tropism in nerve regeneration in vivo. Attraction of regenerating axons by diffusible factors derived from cells in the distal nerve stumps of transected peripheral nerves. Brain Res 253:1-12.

Popko B, Puckett C, Lai E, Shine HD, Readhead C, Takahashi N, Hunt SW, Sidman RL, Hood L (1987) Myelin deficient mice: expression of myelin basic protein and generation of mice with varying levels of myelin. Cell 48:713-721.

Radeke MJ, Misko TP, Hsu C, Herzenberg LA, Shooter EM (1987) Gene transfer and molecular cloning of the rat nerve growth factor receptor. Nature 325:593-597.

Reichert F, Saada A, Rotshenker S (1994) Peripheral nerve injury induces Schwann cells to express two macrophage phenotypes: phagocytosis and the galactose-specific lectin MAC-2. J Neurosci 14:32313245.

Reynolds ML, Woolf CJ (1993) Reciprocal Schwann cell-axon interactions. Curr Opin Neurobiol 3:683-693.

Sanes JR (1989) Extracellular matrix molecules that influence neural development. Annu Rev Neurosci 12:491-516.

Scherer SS, Wang D-Y, Kuhn R, Lemke G, Wrabetz L, Kamholz J (1994) Axons regulate Schwann cell expression of the POU transcription factor SCIP. J Neurosci 14:1930-1942.

Schmalbruch H (1986) Fiber composition of the rat sciatic nerve. Anat Rec 215:71-81.

Shetty VP, Antia NH (1980) Myelination around multiple axons in the 
peripheral nerve: an unusual ultrastructural observation. Acta Neuropathol (Berl) 50:147-151.

Shimozawa A (1975) Quantitative studies on the motor root of the mouse facial nerve. Acta Anat 92:171-177.

Son Y-J, Thompson WJ (1995) Schwann cell processes guide regeneration of peripheral axons. Neuron 14:125-132.

Spencer PS, Thomas PK (1974) Ultrastructural studies of the dying back process. II. The sequestration and removal by Schwann cells and oligodendrocytes of organelles from normal and diseased axons. J Neurocytol 3:763-783.

Stewart HJS, Morgan L, Jessen KR, Mirsky R (1993) Changes in DNA synthesis rate in the Schwann cell lineage in vivo are correlated with the precursor-Schwann cell transition and myelination. Eur J Neurosci 5:1136-1144.

Sunada Y, Bernier SM, Kozak CA, Yamada Y, Campbell K (1994) Deficiency of merosin in dystrophic dy mice and genetic linkage of laminin M chain gene to $d y$ locus. J Biol Chem 269:13729-13732.

Sunderland S (1990) The anatomy and physiology of nerve injury. Muscle Nerve 13:771-784.

Tanaka K, Webster $\mathrm{H}$ deF (1991) Myelinated fiber regeneration after crush injury is retarded in sciatic nerves of aging mice. J Comp Neurol 308:180-187.

Taniuchi M, Clark HB, Johnson EM Jr (1986) Induction of nerve growth factor receptor in Schwann cells after axotomy. Proc Natl Acad Sci USA 83:4094-4098.

Taniuchi M, Clark HB, Schweitzer JB, Johnson EM Jr (1988) Expression of nerve growth factor receptors by Schwann cells of axotomized peripheral nerves: ultrastructural location, suppression by axonal contact, and binding properties. J Neurosci 8:664-681.

Thomson CE, Griffiths IR, Mcculloch MC, Kyriakides E, Barrie JA, Montague $P$ (1993) In vitro studies of axonally-regulated Schwann cell genes during Wallerian degeneration. J Neurocytol 22:590-602.

Toews AD, Griffiths IR, Kyriakides E, Goodrum JF, Eckerman CE, Morell P, Thomson CE (1992) Primary demyelination induced by exposure to Tellurium alters Schwann cell gene expression: a model for intracellular targeting of NGF receptor. J Neurosci 12:3676-3687.

Varon SS, Bunge RP (1978) Trophic mechanisms in the peripheral nervous system. Annu Rev Neurosci 1:327-361.

Venezie RD, Toews AD, Morell P (1995) Macrophage recruitment in different models of nerve injury: lysozyme as a marker for active phagocytosis. J Neurosci Res 40:99-107.

Waxman SG (1968) Peripheral nerve axon processes sharing common myelin sheaths. Brain Res 7:469-473.

Webster H deF (1993) Development of peripheral nerve fibers. In: Peripheral neuropathy, 3d ed (Dyck PJ, Thomas PK, Griffin JW, Luw PA, Poduslo JP, eds), pp 243-266. Philadelphia: Saunders.

Yamada H, Shimizu T, Tanaka T, Campbell KP, Matsumura K (1994) Dystroglycan is a binding protein of laminin and merosin in peripheral nerve. FEBS Lett 352:49-53.

You K-H, Hsieh C-L, Hayes C, Stahl N, Francke U, Popko B (1991) DNA sequence, genomic organization, and chromosomal localization of the mouse peripheral myelin protein zero gene: identification of polymorphic alleles. Genomics 9:751-757.

Zhao Q, Kerns JM (1994) Effects of predegeneration on nerve regeneration through silicone Y-chambers. Brain Res 633:97-104. 